\title{
Kultura, habitus, identitet: rasprava o pretpostavkama politike priznavanja
}

\author{
Saša Puzić \\ Institut za društvena istraživanja u Zagrebu, Hrvatska \\ e-mail:puzic@idi.hr
}

SAŽETAK Osnovni je cilj rada ispitati odabrane elemente multikulturalističke politike priznavanja vodeći računa o međuodnosu kulturno-identitetskih i strukturnih aspekata društvene prakse. U tu se svrhu: 1) predstavljaju ključni koncepti multikulturalističke teorijske pozicije; 2) razmatra se Bourdieuov koncept habitusa, koji upućuje na ograničenja i društvenu deriviranost subjektivnih dispozicija; 3) propituje se odnos pojmova habitusa i identiteta i 4) zahtjevi za priznanjem manjinskih identiteta povezuju se sa zahtjevima za redistribucijom unutar teorijskog okvira N. Fraser. Analiza pokazuje da je oblikovanje postojećih identiteta u smjeru fluidnijih i debinariziranih identitetskih obrazaca važan element za svrsishodno aktiviranje i politiziranje manjinskih identiteta. Taj se proces treba temeljiti na svijesti o strukturalnim limitima svake refleksivne rekonstrukcije identiteta.

Ključne riječi: kultura, habitus, identitet, multikulturalizam, politika priznavanja, politika redistribucije. 


\section{Uvod}

U posljednjih tridesetak godina pojmovi kulture i identiteta zauzimaju središnji položaj u sociologiji i drugim društvenim i humanističkim znanostima. Taj postmodernistički „kulturni zaokret” prisutan je i u raspravama u kojima se propituju društveni identiteti povezani s različitim oblicima društvene nepravde (Bottero, 2010.) - klasnim, etničkim, rodnim ili, primjerice, onima povezanima s ograničenim tjelesnim sposobnostima (engl. disability). Umjesto da se tretiraju kao konačne kategorije, ti se identiteti i s njima povezani odnosi dominacije i podređenosti tumače kao kulturni artefakti dominantnih diskursa unutar obitelji, obrazovanja ili države, čemu se, kao organizirajući koncept borbe za prava i mogućnosti zakinutih manjina (etničkih, rasnih, seksualnih, rodnih i dr.) najčešće suprotstavlja neki oblik politike identiteta ${ }^{1}$ (engl. identity politics) (Lauder i sur., 2006.; usp. Chua, 2018.). Opisano stajalište polazi od koncepta moći povezanog $s$ jezikom i kulturnim aspektima svakodnevnog života nasuprot modernističkom naglašavanju materijalnih struktura kao primarnog izvora nepravednih društvenih odnosa. Sukladno tome, pojedinci se promatraju kao aktivni akteri koji, usprkos podređenom društvenom položaju, mogu svojim djelovanjem preoblikovati postojeće manjinske identitete i na taj način suprotstaviti se marginalizaciji i društvenom isključivanju (Bottero, 2010.). S druge strane, autori koji kritiziraju opisanu postmodernističku paradigmu upozoravaju na njezino umanjivanje važnosti ekonomskih uvjeta društvenog isključivanja i stigmatizacije manjinskih grupa te podsjećaju na to da se razlike u statusu pojedinih kultura i identiteta u pravilu vežu uz različite stupnjeve monopolizacije materijalnih dobara i šansi kao jednako objektivnih izvora moći u društvu (Lauder i sur., 2006.; usp. Weber, 1980.).

Smatramo da se navedena pitanja kulture i identiteta i njihove socioekonomske ukorijenjenosti mogu razumjeti kao uzajamna uvjetovanost društvenih struktura i struktura svijesti, pri čemu i kulturno posredovana značenja i simboli i društvena distribucija materijalnih resursa mogu poticati i usmjeravati, ali i ograničavati društveno djelovanje. Sukladno tome, osnovni je cilj rada ispitati odabrane elemente multikulturalističke politike priznavanja (engl. politics of recognition) kao dominantnog pristupa politike identiteta (usp. McNay, 2008b.), vodeći računa o međuodnosu kulturnoidentitetskih i strukturnih aspekata društvene prakse. U tu se svrhu prvo predstavljaju osnovni ciljevi i središnji pojmovi multikulturalističke teorijske pozicije. U drugom se koraku uvodi koncept habitusa, koji upućuje na ograničenja društvene prakse vezano uz društvenu deriviranost subjektivnih dispozicija i zapostavljanje veza između postojećih obrazaca različitosti i nejednakosti u društvu. Nakon toga propituje se odnos habitusa i identiteta kao „sjecišta kritičke svijesti, kolektivnog djelovanja i potencijala za promjenu" (Morrow i Torres, 1995.). Na kraju se zahtjevi za priznanjem manjinskih

1 Politika identiteta kao oblik političkog djelovanja u kojem se zahtijeva javno priznavanje manjinskih identiteta, odnosno priznavanje (sociokulturne) različitosti na osnovu koje se ti identiteti uspostavljaju. Opširnije vidi sljedeće poglavlje. 
identiteta dovode u vezu sa zahtjevima za politikom redistribucije unutar analitičkog okvira N. Fraser (1997.).

\section{Pitanje identiteta i multikulturalistička politika priznavanja}

Ideja multikulturalizma veže se s jedne strane uz sociokulturnu raznolikost modernih društava, a s druge strane uz činjenicu da je ova raznolikost u prošlosti često bila ignorirana i potiskivana. Stoga su pripadnici različitih manjinskih grupa (npr. imigranti, pripadnici LGBT zajednice) koji su odstupali od vladajućih kulturnih obrazaca dominantnoga društva često bili izloženi diskriminaciji, marginalizaciji i asimilaciji (Mesić, 2006.). Koncept multikulturalizma razvio se kao reakcija na takav razvoj, pri čemu pripadnici manjinskih grupa odbijaju biti definirani kao „devijantni” zbog svoje etničke pripadnosti, roda ili seksualne orijentacije (Kymlicka, 2002.). Multikulturalističke politike pritom odbacuju tradicionalne statusne hijerarhije između grupa (temeljene na vjeri, etničkoj pripadnosti, rodu, seksualnoj orijentaciji i drugim askriptivnim kriterijima) kao i na njima utemeljen privilegirani ili podređeni položaj u društvu. Ističe se da se za razliku od ranijih emancipatorskih koncepcija u kojima se uglavnom isticao ekonomski interes podređenih klasa, racionala multikulturalizma zasniva na borbi protiv diskriminacije i društvenom priznavanju manjinskih identiteta (Parekh, 2006.; Kelly, 2002.; Cooke, 2009.). Zbog toga se iz multikulturalističke perspektive problematika identiteta ne ograničava na subjektivno pitanje samodoživljaja pojedinca, već je ona uvijek i društveno i političko pitanje (usp. Isin i Wood, 1999.).

Središnje pitanje identiteta - u smislu odabranih ili naslijeđenih karakteristika koje definiraju pojedince i grupe i koje utječu na njihovo samorazumijevanje - veže se uz društveno priznavanje manjinskih kultura (Parekh, 2006.). Multikulturalisti kulturu shvaćaju kao organizirajući princip individualnog i kolektivnog života te naglašavaju kulturnu ukorijenjenost pojedinca bez koje bi on bio samo „prazna ljuštura, dezorijentirana monada" (Mesić, 2006.:46; Parekh, 2006.). Kao povezani skup vjerovanja i praksi kultura pojedincima osigurava smislenu orijentaciju, što znači da je autonomija pojedinaca (shvaćena kao sposobnost donošenja moralno ispravnih izbora) povezana $s$,pristupom njihovoj kulturi, s prosperitetom i razvojem njihove kulture te $s$ poštovanjem što ga drugi iskazuju prema njihovoj kulturi” (Kymlicka, 2002.:339). Stoga se naglašava da prava pojedinaca ovise o pravu grupe na kulturnu različitost i samobitnost. Ako ta različitost nije zajamčena, uskraćivanje priznanja grupi praktično znači podčinjavanje manjina. Takvo se stajalište obrazlaže tvrdnjom da uskraćivanje priznanja u osnovi znači da se pripadnike manjina ometa u slobodnom razvoju njihova identiteta (Taylor, 1994., Mesić, 2006.). Razlog tome je što drugi naš identitet barem dijelom oblikuju priznavanjem (engl. recognition), nepriznavanjem ili iskrivljenim priznanjem (engl. misrecognition) (Taylor, 1994.). Time se želi reći da se razvoj identiteta ne zbiva u izolaciji, već da se uspostavlja „dijaloški” kroz odnose s drugima. Priznanje „drugih” stoga je neophodno za razvoj zdrave i pozitivne predodžbe koju pojedinci 
imaju o sebi (Fraser, 2000.; Mead, 2003.). S druge strane, uskraćivanje priznanja od društvene okoline može biti oblik opresije jer „osoba ili grupa može otrpjeti istinsku štetu, istinsku deformaciju, ako okolina ili društvo zrcali ograničenu, ponižavajuću ili prezirnu sliku njih samih" (Taylor, 1994.:25). Multikulturalisti pritom ističu da je takva nipodaštavajuća slika o sebi odraz prezira šireg društva, koji svoj izraz nalazi u asimilacijskim praksama u javnoj sferi (npr. od strane političkih, obrazovnih ili kulturnih institucija) (usp. Kymlicka, 2003.). To objašnjava zašto pripadnici manjinskih grupa koji misle da su stigmatizirani i isključeni iz matice društva i dominantne kulture traže različite oblike javnog priznavanja svoje različitosti (što podrazumijeva njezino prihvaćanje, poštovanje i javnu afirmaciju) uključujući zahtjeve za legalno-pravnom zaštitom svojih kultura (Kymlicka, 2002.; Parekh, 2006.).

Unutar multikulturalističkog diskursa zahtjevi za priznanjem identitetski relevantnih razlika nerijetko se predstavljaju kao izraz borbe za jednakost, samoodređenje i dostojanstvo nasuprot većinskoj dominaciji i podčinjavanju „Drugih i drugačijih” (Parekh, 2006.). Pored isticanja važnosti kultura za oblikovanje identiteta pojedinaca, takav stav uključuje kulturno-relativističko stajalište da su, načelno, sve kulture jednako vrijedne te da imaju pravo na poštovanje svoje različitosti (Kelly, 2002.). Sukladno tome - a suprotno liberalnoj tvrdnji o individualnim pravima kao jedinoj legitimnoj osnovi prevladavanja diskriminacije - multikulturalisti ističu da se kulturne razlike najbolje mogu uvažiti ako pripadnici manjinskih kultura posjeduju određena grupno-specifična prava (Mesić, 2006.; usp. Isin i Wood, 1999.). Zagovornici multikulturalizma pritom tvrde da ni demokratski politički proces, a još manje tržište, ne mogu osigurati dugoročni opstanak manjinskih kultura jer praktična realizacija individualnih prava nikada nije etički neutralna (Habermas, 1994.). Sukladno tome, multikulturalisti klasičnom liberalnom modelu zamjeraju inzistiranje na kulturno pristranoj primjeni pravila koja određuju individualna prava te ističu da je liberalna podozrivost prema kolektivnim pravima inkompatibilna s multikulturalnom politikom identiteta.

Kada je riječ o priznavanju grupnih prava i identiteta često se navodi stajalište C. Taylora (1994.) koji se referira na borbu frankofonih Kanađana za autonomiju i priznavanje njihove kulturne posebnosti. Taylor svoju teorijsku poziciju gradi na premisi da priznavanje identiteta u osnovi zahtijeva „da svi priznamo jednaku vrijednost različitih kultura; ne samo da im dopustimo da prežive, već da im potvrdimo njihovu vrijednost" (Taylor, 1994.:64). U praksi, prema Tayloru, takvo stajalište zahtijeva da se tradicionalnom liberalizmu „slijepom za razlike” suprotstavi model koji osigurava „kulturno preživljavanje” i ostvarivanje zajedničkih ciljeva (povezanih sa sudovima o tome što čini dobar život) i koji istovremeno jamči univerzalno važenje određenih prava. Prema tome autoru su ograničenja individualnih prava (kao primjere takvih ograničenja navodi obvezno korištenje francuskog jezika u komercijalnom oglašavanju ili u većim poduzećima u kanadskoj provinciji Quebec) opravdana jedino ako se zakonska ograničenja uvode radi očuvanja kolektivnog identiteta (u navedenom pri- 
mjeru kolektivnog identiteta frankofonih Kanađana u Quebecu unutar većinski anglofone Kanade). No i tada osnovna individualna prava, kao što su sloboda govora ili sloboda udruživanja, ostaju zajamčena. U konačnici, sam Taylor ne razrješava osnovnu dilemu između individualnih prava i kolektivnih ciljeva jer se prema njegovu mišljenju važenje načela jednakosti u odnosu na „važnost preživljavanja određene kulture” treba razmatrati od slučaja do slučaja. Smatramo da se razlozi za tako nedosljedan zaključak nalaze u tome što Taylor, $s$ jedne strane, naglašava središnju važnost kulture za priznavanje identiteta, no istovremeno prelazi preko činjenice da priznavanje identiteta predstavlja trajan proces u kojem određene kulturne karakteristike mogu, ali i ne moraju biti relevantne za identitet pojedinca. Štoviše, Taylorovo naglašavanje važnosti očuvanja kolektivnog identiteta u smislu „kulturnog preživljavanja” otvara mogućnost da se identiteti shvaćaju redukcionistički i pojednostavljeno te da se prešutno prelazi preko mogućih identitetskih razlika unutar manjinskih grupa. Posljedica je toga da se, $\mathrm{u}$ ime jednog proklamiranog zajedničkog identiteta, na pojedince vrši moralni pritisak kako bi se prilagodili danoj kulturi (Fraser, 2000.; usp. Cooke, 2009.). Kritičari stoga upozoravaju na postvarujuće tendencije tako shvaćene politike priznavanja te navode da umjesto emancipacije može proizvesti netoleranciju, autoritarnost i potiskivanje raznolikosti unutar grupe (Barry, 2006.). S obzirom na navedene kritike, smatramo da je za pravilno razumijevanje važnosti pojedinih identitetskih elemenata potrebno ukazati na razlikovanje identiteta od kulturne uvjetovanosti ili habitusa.

\section{Habitus}

U stručnoj se literaturi pojam habitusa veže uz rad sociologa P. Bourdieua (v. Swartz, 1997.; Mouzelis. 2000.). On razvija ovaj koncept u sklopu svoje teorije prakse pokušavajući izbjeći krajnosti objektivističke („društvo stvara pojedince”) i subjektivističke („pojedinci stvaraju društvo") perspektive u objašnjenju odnosa između pojedinca i društva (Bourdieu, 2011.). Bourdieu postulira da se individualno mišljenje i djelovanje ne mogu objasniti samo karakteristikama pojedinaca (znanja, namjere, motivi i dr.) jer se ono o čemu ljudi misle i ono što rade uspostavlja na osnovi društveno i historijski deriviranih dispozicija. Te se dispozicije, kao tendencije k određenom tipu mišljenja i djelovanja, prenose i usvajaju tijekom primarne socijalizacije te se kasnije kontinuirano nadograđuju u interakciji s društvenom okolinom (unutar vršnjačkih grupa, u školi i dr.). Najvažniji rezultat socijalizacijskih procesa, kako ističe Bourdieu, stvaranje je habitusa kao sustava „trajnih i prilagodljivih dispozicija koji, integrirajući prošlo iskustvo, funkcionira u svakom trenutku kao matrica percepcije, mišljenja i djelovanja" (Bourdieu, 1977.:82-83). Jednostavnije rečeno, u osnovi toga koncepta nalazi se pretpostavka prema kojoj ljudi koji u određenim grupama (obitelj, etnička grupa, klasa i dr.) žive u sličnim uvjetima razvijaju zajednički način promatranja svijeta i djelovanja. Sukladno tome, habitus oblikuje mišljenje i djelovanje pojedinaca, i to tako da pored individualnog iskustva utjelovljuje kolektivno iskustvo obitelji, klase ili etničke grupe kojoj netko pripada (Shim, 2012.). 
Prema Bourdieu, habitus utjelovljuje temeljnu korespondenciju društvenog položaja i mentalnih struktura, pri čemu elementi strukturiranog društvenog prostora (obrazovanje, politika, umjetnost i dr.), koji Bourdieu naziva polje, postaju elementima habitusa (Bourdieu i Wacquant, 1992.). Budući da se habitus formira unutar određenog polja, njihov je odnos homologan: „Polje se sastoji od skupa objektivnih, povijesnih veza između položaja osiguranih određenim oblicima moći (ili kapitala), dok se habitus sastoji od skupa povijesnih veza 'odloženih' unutar pojedinačnih tijela u obliku mentalnih matrica percepcije, vrednovanja i djelovanja” (Bourdieu i Wacquant, 1992.:16; usp. Sorić, 2012.). U osnovi, to znači da su kognitivne strukture koje pojedinci rutinski primjenjuju u svome svakodnevnom praktičnom djelovanju utjelovljene društvene strukture (Bourdieu, 2011.). Kao stečeni sustav generativnih matrica mišljenja, percepcije i djelovanja, habitus je postojaniji od individualnih interesa i želja (Bourdieu, 1990.). Postojanost habitusa objašnjava se time što se elementi društvenih struktura internaliziraju kroz svakodnevne prakse koje se doimaju prirodnim i samorazumljivim. Habitus se stoga ispoljava bez svjesnog razmišljanja o ciljevima ili postupcima nužnim za njihovo ostvarenje (Bourdieu, 2011.). Na taj način habitus „neprimjetno” pobuđuje pojedince na određeno djelovanje ili na određene odabire koji se kao takvi čine samorazumljivim i prirodnim.

Zbog opisane „prirodnosti” habitusa društvene nejednakosti mogu u očima pojedinaca iz klasno ili statusno deprivilegiranih grupa izgledati smislene i opravdane (Swartz, 1997.). Razlog tome je što je habitus proizvod pretežno nesvjesne internalizacije objektivnih mogućnosti koje dijele pripadnici određene društvene grupe: „[Habitus je] utjelovljena nužnost pretvorena u generativnu dispoziciju... Kad je nužnost učinjena vrlinom, on [habitus] neprestano ide za tim da nužnost pretvori u vrlinu, naginjući „izborima“ prilagođenima uvjetima kojih je on proizvod...” (Bourdieu, 2011.:158, 161). Samim time pojedinci iz klasno ili statusno deprivilegiranih grupa prilagođavaju svoje aspiracije ograničenim mogućnostima te u konačnici „nalaze” svoje „mjesto u društvu”. Oni „oblikuju svoje aspiracije prema konkretnim pokazateljima o tome što je dostupno i što nije, o tome što je i što nije 'za nas'” (Bourdieu, 1990.:64).

Iako se, prema Bourdieu, pojedinci prilagođavaju novim situacijama, njihov se habitus prije modificira nego što se u osnovi mijenja. Takvo se stanje objašnjava činjenicom da je utjecaj primarne socijalizacije na unutarnje dispozicije dublji i trajniji od kasnijih socijalizacijskih iskustava (Swartz, 1997.). Referirajući se na navedenu „inertnost” habitusa, kritičari taj koncept u konačnici opisuju kao oblik strukturalnog determinizma u kojem habitus izravno odražava objektivne uvjete u kojima je nastao. Shodno tome, „izvor djelovanja pojedinaca ne leži u njihovoj interakciji s drugim pojedincima, već u objektivnim strukturama koje im se suprotstavljaju” (King, 2000.:423.). Bourdieu se zamjera što odnos između struktura, habitusa i društvene prakse postavlja kao odnos determinacije u kojem analitički naglasak leži više na uzrocima nego na razlozima djelovanja (Jenkins, 1982.). Nasuprot tome, zagovornici Bourdieuove teorije smatraju da habitus pojedincima ostavlja prostor za brojne različite reakcije u nekoj situaciji 
(McNay, 2008a.; Swartz, 1997.). Naglašava se da habitus upućuje na teoriju djelovanja koja je više praktična nego diskurzivna, predrefleksivna prije nego svjesna te istodobno reproduktivna i generativna. Pritom se ističe da generativni karakter habitusa odlikuje dvostruki odnos s njegovim društvenim kontekstom, odnosno poljem u kojem nastaje. Taj se odnos s jedne strane sastoji od odnosa kondicioniranja u kojem objektivni uvjeti polja oblikuju habitus, a s druge strane od odnosa „kognitivne konstrukcije” u sklopu kojeg habitus polju osigurava smisao i važenje (McNay, 1999.). Ako habitus i polje odgovaraju jedno drugom, djelovanje aktera ostaje predvidljivo i nereflektirano. No ako se ta homologija dovede u pitanje (npr. prijelazom u drugo polje), raste mogućnost osvještavanja automatiziranih interakcija s poljem i mogućnost promjena u samom polju (Sorić, 2012.). U tom se smislu naglašava da strukturalna reprodukcija nije izravan odraz habitusa, već, u bitnome, rezultat praktične prilagodbe na ograničene klasne ili statusne mogućnosti (Swartz, 1997.). Ukratko, zagovornici Bourdieuove teorije naglašavaju da habitus valja razumjeti, ne kao načelo determinacije, već kao generativnu strukturu koja društveno djelovanje istodobno uvjetuje i omogućava (McNay, 1999.).

\section{Razlikovanje habitusa $i$ identiteta}

Neredukcionističko tretiranje pojmova habitusa i identiteta podrazumijeva da se nečiji kulturom oblikovan identitet ne smije izjednačavati s činjenicom da je svaki pojedinac nužno obilježen svojom kulturom. Kulturna uvjetovanost označava habitus, kao utjelovljene dispozicije u obliku matrica percepcije, mišljenja i djelovanja, dok se društveni identitet kao „naše razumijevanje onoga tko smo i tko su drugi ljudi, te recipročno razumijevanje drugih ljudi toga tko su oni i drugi” (Jenkins, 1996.:5), zasniva na tumačenju i intersubjektivnom priznavanju habitusa (Auernheimer, 2003.). Drugim riječima, društveni identiteti proizlaze iz osviještenog i reflektirajućeg sučeljavanja $s$ kulturno određenim habitusom. Pritom se identiteti u pravilu problematiziraju u susretu sa stranim i drugačijim identitetima ili u odnosima između grupa unutar različitih polja, uslijed marginalizacije i stigmatizacije pojedinih manjinskih identiteta i kultura. Razlog tome je što i u jednom i u drugom slučaju dolazi do određenog narušavanja utjelovljenih dispozicija, što proizvodi tendenciju ka njihovu osvještavanju (Bottero, 2010.). U tom smislu H. Bradley (2016.) razlikuje tri razine identiteta, što, sukladno rečenom, možemo prevesti kao tri razine sučeljavanja s kulturno određenim habitusom. Prema toj autorici pasiuni identiteti jesu potencijalni identiteti koji proizlaze iz društvenih veza i odnosa u koje su pojedinci uključeni (npr. etničkih ili klasnih), a kojih nisu posebno svjesni. Pojedinci te identitete posebno ne ističu niti ih aktivno izražavaju, osim kada se dogodi nešto iznimno što te identitete naglašava i izbaci u prvi plan. Aktivni identiteti jesu identiteti kojih su pojedinci svjesni i na temelju kojih ti pojedinci djeluju. Oni čine pozitivne elemente u nečijoj samoidentifikaciji, iako nije nužno da stalno mislimo o sebi u okviru nekog određenog identiteta. Tako, primjerice, za ženu rodni identitet može biti izvor aktivnog obrambenog identiteta u slučaju seksualnog uznemiravanja, dok u drugim prilikama o sebi ne mora misliti u 
kontekstu roda. Sukladno tome, aktivni se identiteti javljaju kao obrambena reakcija na negativnu definiciju i iskustvo diskriminacije. Politizirani identiteti javljaju se kada pojedinci stalno misle o sebi u okviru nekog identiteta i kada ti identiteti osiguravaju trajnu osnovu za djelovanje. Politizirani identiteti nastaju političkim djelovanjem, pri čemu ti identiteti osiguravaju osnovu za obranu ili afirmaciju prava i interesa neke grupe. U tom se sklopu, primjerice, rod, seksualna orijentacija ili etnička pripadnost mogu pretvoriti u osnovu za organiziranje kolektivne akcije.

Navedeno razlikovanje triju razina identiteta upućuje na činjenicu da se kolektivno iskustvo društvene nepravde ne pretvara automatski u „oporbenu osviještenost” i kolektivno djelovanje (McNay, 2008a.). Drugim riječima, aktivni i politizirani identiteti su, za razliku od pasivnih identiteta, nešto o čemu se nužno reflektira i pregovara. Pregovaranje i uspostavu aktivnih i/ili politiziranih identiteta otežava činjenica što društvene intervencije za afirmaciju grupnih interesa mogu imati različita polazišta i različite učinke: „Postoji značajna razlika između prepoznavanja nepravde, identificiranja sistemske dominacije i zajedničkih interesa, predlaganja strategija za kolektivnu akciju, i konačno osjećaja spremnosti za djelovanje” (McNay, 2008a.:281). Osvještavanje identiteta dodatno se usložnjava zbog spontane prilagodbe habitusa „objektivnim šansama” kao manjinskim statusom ograničenim mogućnostima djelovanja (Bourdieu, 2011.). To znači da priznavanje manjinskih identiteta može predstavljati iskrivljeno priznavanje (engl. misrecognition) koje podrazumijeva da pripadnici manjina mogu težiti afirmaciji upravo onih vrijednosti koje ih definiraju kao podređene (Bourdieu i Wacquant, 1992.). Prema Bourdieu, takvo priznavanje predstavlja oblik „simboličkog nasilja”, odnosno „otuđenu kogniciju koja svijet vidi kroz kategorije koje joj taj svijet nameće i koja društveni svijet shvaća kao prirodni svijet” (Bourdieu, 1990.:140-141). Pojedinci pritom arbitrarnu prirodu manjinskog habitusa percipiraju kao samorazumljivu i neizbježnu, pri čemu se aktivni i/ili politizirani identiteti poimaju u opoziciji spram dominantnih vrijednosnih obrazaca i većinskih identiteta, primjerice, prema strategiji black is beautiful (Bourdieu, 2011.; usp. Ogbu, 1982.). S druge strane, ako razina osviještenosti ostane na razini pasivnih identiteta, pojedinci mogu svoj podređeni položaj internalizirati kao „habitus rezignacije, frustriranog bijesa i dosade” (McNay, 2008a.:281) ili mogu težiti usvajanju dominantnih identitetskih obrazaca, što je suprotno težnji za kolektivnom emancipacijom i stjecanjem kontrole nad društvenim identitetom. Ili, kako navodi Bourdieu, u područjima koja se ne konstituiraju politički „dominiranima ostaje samo alternativa vjernosti sebi i grupi (uvijek izložena vraćanju stida od samoga sebe) i individualnog napora da se usvoji dominantan ideal, oprečan samoj ambiciji ponovnog uzimanja u zajedničke ruke društvenog identiteta (one vrste koju traži zajednički revolt američkih feministica kad slavi natural look)" (Bourdieu, 2011.:354).

2 Pod pojmom Black is beautiful odnosno, u prijevodu, crno je lijepo misli se na kulturni pokret koji se 60-ih godina 20. st. pojavljuje u SAD i kojim se zalaže za javnu afirmaciju afroameričkog identiteta i „crne” kulture općenito (npr. u filmu, modi ili glazbi) naspram opresivne tzv. WASP (engl. White AngloSaxon Protestant) kulture većinske bjelačke zajednice (Mesić, 1998.). 
Zavisno od toga o kojem je tipu identiteta riječ (pasivni, aktivni, politizirani), kulturne se specifičnosti u sadržajnom smislu mogu esencijalizirati, negirati ili selektivno interpretirati (Auernheimer, 2003.). Kod toga navedeno kulturno prepoznavanje grupa i pojedinaca ovisi i o njihovim povijesnim i kulturnim narativima, odnosno o tome kako se ti narativi društveno kontekstualiziraju i interpretiraju. Općenito vrijedi da grupni narativi mogu u većoj ili manjoj mjeri naglašavati sociokulturnu inkompatibilnost grupe prema drugim grupama, no mogu također težiti nadilaženju granica među grupama. Potonja se mogućnost veže uz činjenicu da kulture u sebi sadrže različite dimenzije od kojih je svaka izložena kontinuiranom propitivanju i mogućim reinterpretacijama. S druge strane, postoje također zajednički narativi koji su prisutni u različitim kulturama i koji pružaju osnovu za uzajamno razumijevanje (McNay, 2008b.). Sukladno tome, pojedini autori navode mogućnost „hibridizacije”, odnosno usvajanja višestrukih kulturnih identiteta koji se kontinuirano (re)produciraju transformacijom i različitošću (Mesić, 2006.). S tim u vezi može se navesti stajalište S. Halla (1990.), koji mogućnost hibridizacije povezuje s potencijalom za promjenu: „Kulturni identitet $[\ldots]$ označava 'postajanje' kao i 'bivanje'... Kulturni identiteti dolaze odnekud i imaju svoje povijesti. No, kao i sve povijesno, oni se neprekidno mijenjaju. Umjesto da su vječno fiksirani u nekoj esencijaliziranoj prošlosti, oni su predmet trajne 'međuigre' povijesti, kulture i moći [...] identiteti su ona imena koja pridajemo različitim načinima kako smo pozicionirani, i kako se pozicioniramo, unutar narativa prošlosti” (Hall, 1990.:225). Iako složenost tako shvaćenih identiteta tendencijski nadilazi binarnu (mi - oni) strukturu tradicionalnih identitetskih predodžbi, Hall, poput Bourdieua, ukazuje na mogućnost njihova iskrivljenog priznavanja. Kao primjer potonjeg Hall navodi internaliziranje dominantnog kolonijalnog diskursa od strane podređenih grupa (i pritom se poziva na iskustvo crnih karipskih zajednica), čiji su pripadnici sami sebe doživljavali kao „Druge i drugačije“ (engl. the Other). U tom kontekstu Hall ističe da usvajanje nametnutih identitetskih predodžbi (u sklopu dominantnih diskursa) potencijalno „osakaćuje i izobličava” sliku koju pojedinci imaju o sebi, a što u konačnici potiče subjektivnu prilagodbu postojećem poretku. U kojoj mjeri kulturni identiteti potencijalno korespondiraju ili kolidiraju s normativnim poretkom ovisi, između ostalog, o relevantnim odnosima moći.

\section{Priznavanje i redistribucija prema Nancy Fraser}

Razmatrano razlikovanje pojmova habitusa i identiteta upućuje na složenu prirodu sociokulturne subordinacije manjinskih grupa. $S$ jedne je strane istaknuto da iskustvo društvene nepravde ne jamči zahtjeve za priznavanjem i „oporbenu osviještenost”, a $s$ druge strane da samo priznavanje može predstavljati oblik iskrivljenog priznavanja (engl. misrecognition). Razlog je i jednog i drugog što pripadnici manjina arbitrarnost manjinskog habitusa tendencijski percipiraju kao nešto prirodno i neupitno, pri čemu se njihove težnje oblikuju prema njihovu egzistencijalnom iskustvu i konkretnim pokazateljima o tome što je dostupno i što nije (Bourdieu, 1990.). Takvo gledište u 
osnovi znači da se zahtjevi za priznavanjem manjinskih identiteta ne mogu odvojiti od materijalnih uvjeta u kojima se ti identiteti pojavljuju. O tome govori N. Fraser (1997.) kada jednostranu „politiku priznavanja” optužuje za nekritičko slavljenje različitosti i ignoriranje „politike redistribucije”, odnosno za zapostavljanje mogućih veza između postojećih obrazaca različitosti i nejednakosti u društvu.

Fraser (1997.) ističe da, idealtipski promatrano, u suvremenim društvima postoje dvije osnovne vrste društvene nepravde koje su povezana s dva oblika političke borbe. Jedna je materijalna ili socioekonomska nepravda, koja je ukorijenjena u ekonomskoj strukturi društva i uključuje eksploataciju (prisvajanje proizvoda nečijeg rada od strane drugih), ekonomsku marginalizaciju (ograničavanje na nepoželjne vrste poslova ili potpuno isključivanje iz tržišta rada) i ekonomsku deprivaciju (uskraćivanje primjerenog standarda života). Osnovno sredstvo za ispravljanje socioekonomske nepravde jest ekonomsko restrukturiranje, koje može uključivati preraspodjelu dohotka, reorganizaciju podjele rada ili, primjerice, demokratizaciju ekonomskog odlučivanja. Fraser taj skup politika naziva politika redistribucije (engl. the politics of redistribution). Druga vrsta društvene nepravde jest kulturna ili simbolička nepravda, koja je ukorijenjena u društvenim obrascima predočavanja, tumačenja i komuniciranja i koja uključuje kulturnu dominaciju (podvrgavanje obrascima tumačenja i komunikacije neke druge suprotstavljene kulture), nepriznavanje (činiti se nevidljivim u autoritativnim komunikativnim praksama određene kulture) i nepoštovanje (biti difamiran ili omalovažen u stereotipnim javnim kulturnim predodžbama ili u svakodnevnom životu). Osnovno sredstvo za ispravljanje kulturne nepravde kulturna je ili simbolička promjena, koja može uključivati pozitivnu revalorizaciju omalovaženih identiteta i kultura te pozitivno vrednovanje kulturne raznolikosti. Taj skup politika Fraser naziva politika priznavanja (engl. the politics of recognition). Autorica naglašava da je opisana distinkcija između socioekonomske i kulturne nepravde prvenstveno analitička te da su u praksi one uzajamno isprepletene: ekonomske su institucije uvijek prožete značenjima i normama i kao takve imaju konstitutivnu i nesvodivu kulturnu dimenziju - obrnuto, čak i najdiskurzivnije kulturne prakse imaju materijalno uporište i ne mogu se odvojiti od svoje ekonomske dimenzije (Fraser, 1997.). Primjerice, kada je riječ o „rasnim” podjelama (što analogno može vrijediti i za etničke podjele), Fraser navodi da ekonomski i kulturni faktori stvaraju svojevrsni začarani krug u kojem ekonomska podređenost ograničava pripadnike „rasnih” manjina da dignu svoj „glas” i da se suprotstave rasističkim i eurocentričnim kulturnim normama institucionaliziranim u ekonomiji: „'Rasa' strukturira kapitalističku podjelu rada. Ona strukturira podjelu unutar plaćenog rada između slabo plaćenih, manualnih, prljavih, jednostavnih zanimanja s niskim statusom, koja su iznadproporcionalno zastupljena među obojenima, i bolje plaćenih, činovničkih, profesionalnih, tehničkih i menadžerskih zanimanja $s$ višim statusom, koja su iznadproporcionalno zastupljena među 'bijelcima'... Uz to ide kulturni rasizam: sveprisutno podcjenjivanje i omalovažavanje stvari označenih kao 'crno', 'smeđe' i 'žuto'” (Fraser, 1997.:21-22). 
S obzirom na spomenutu isprepletenost ekonomskih i kulturnih praksi, Fraser se zalaže za kritičku teoriju priznavanja, koja podržava samo one verzije identitetskih politika koje se mogu koherentno kombinirati s politikom društvene jednakosti. Također ističe da „[r]adikalni demokrate neće nikada uspjeti razmrsiti gordijski čvor identiteta i različitosti, dok se ne napusti teren politike identiteta. To pretpostavlja resituiranje kulturne politike u odnosu na socijalnu politiku i vezanje zahtjeva za priznanjem uz zahtjeve za redistribucijom" (Fraser, 1997.:174; usp. Barry, 2006.). Fraser pritom razlikuje dva osnovna pristupa koji karakteriziraju moguće politike redistribucije i priznavanja: 1) afirmativni pristup, koji podrazumijeva postupke (engl. remedies) namijenjene ispravljanju nepravednih ishoda bez promjene strukture koja te ishode generira i 2) transformativni pristup, koji cilja na ispravljanje nepravednih ishoda restrukturiranjem temeljnog generativnog okvira. U tom smislu Fraser odbacuje afirmativni pristup multikulturalizmu (u čije predstavnike svrstava i C. Taylora) i zalaže se umjesto toga za transformativni multikulturalizam, koji bi uključivao borbu za društvenu jednakost. Pritom ističe da jedan (afirmativni pristup) nastoji osnažiti podcijenjene grupne identitete tako što njihov sadržaj, kao i razlikovanja koja ih podupiru, tretira kao dane, čime ih esencijalizira, dok drugi (transformativni pristup) priznavanje različitosti povezuje $s$ transformacijom simboličke i ekonomske strukture postojećih društvenih podjela. U konačnici, afirmativni multikulturalizam rezultira osnaživanjem postojećih grupnih razlika, dok njegov transformativni korelat (dugoročno) otvara prostor za nova kulturna i ekonomska grupiranja (Fraser, 1997.:23-25). ${ }^{3}$ Iz prije adresirane Bourdieuovske perspektive, afirmativni multukulturalizam o kojem govori N. Fraser povećava mogućnost iskrivljenog priznavanja manjinskih identiteta jer se zahtjevi za priznavanjem temelje na postojećim, habitusno utemeljenim, simboličkim dihotomijama. Nasuprot tome, u mjeri u kojoj uspijeva potkopati postojeće simboličke podjele na relaciji većina - manjina, transformativni multikulturalizam potencijalno potkopava postojeću homologiju habitusa i društvenog polja i vice versa. Time se širi prostor za kritički pristup politici identiteta što uključuje i adresiranje odnosa nejednakosti unutar manjinskih grupa (primjerice, po klasnoj, rodnoj ili etničkoj osnovi). U tom smislu različiti autori (npr. Bell, 2016.; Bradley, 2016.) ukazuju na koncept intersekcionalnosti (Crenshaw, 1991., prema Bradley, 2016.), koji pokazuje kako kombinirano djelovanje različitih manjinskih identiteta proizvodi intenzivne i specifične oblike podređenosti - primjerice, za „crne” žene u SAD u usporedbi $s$,crnim” muškarcima ili „bijelim” ženama.

3 Kao ilustraciju razlikovanja afirmativnog i transformativnog pristupa Fraser (1997.) navodi razliku između gay-politike identiteta (engl. gay-identity politics) i pristupa na osnovi queer teorije. Dok prva ima za cilj afirmirati postojeće gej i lezbijske identitete kao takve, druga nastoji dekonstruirati tradicionalnu homo - hetero dihotomiju u korist višestrukih debinariziranih i fluidnijih seksualnih identiteta. Kada je riječ o ekonomskim odnosima, Fraser navodi da afirmativni pristup odgovara realokacijskim politikama liberalne države blagostanja, dok transformativni pristup implicira dublje restrukturiranje proizvodnih odnosa. Afirmativne politike u konačnici potvrđuju grupne razlike (primjerice, tako što se ekonomski najranjivije skupine prikazuju inherentno deficijentnim), dok ih one transformativne dovode u pitanje (primjerice, tako što se pokušava svima osigurati pristup zaposlenju). 


\section{Zaključak}

Uvodno je navedeno da je cilj rada ispitati međuodnos kulturno-identitetskih i strukturnih aspekata društvene prakse na primjeru multikulturalističke politike priznavanja (engl. politics of recognition). U tu su svrhu prvo predstavljeni osnovni ciljevi i najvažniji pojmovi multikulturalističke teorijske pozicije. Istaknuto je da se za razliku od drugih emancipatorskih koncepcija, u kojima se u pravilu isticao ekonomski interes podređenih klasa, racionala multikulturalizma zasniva na borbi protiv diskriminacije različitih manjina (rodnih, etničkih, seksualnih i dr.) i društvenom priznavanju manjinskih identiteta (Kymlicka, 2002.; Parekh, 2006.). Pritom se navodi da uskraćivanje priznanja može biti oblik opresije kada, zbog stalnog suočavanja sa stigmatizirajućim porukama dominantne kulture, pripadnici manjina usvajaju negativnu i sputavajuću sliku o sebi. Prema zastupnicima multikulturalizma, pojedinci i manjinske grupe trebaju odbaciti takve negativne identitete $\mathrm{i}$ iskrivljene predodžbe te umjesto toga zahtijevati javno priznavanje svoje kulturne različitosti. $S$ tim u vezi su istaknuta dva kritička momenta nasuprot multikulturalističke pozicije. Prvi se odnosi na zapostavljanje mogućih veza između postojećih obrazaca različitosti i nejednakosti u društvu, odnosno zanemarivanje politike redistribucije u korist politike priznavanja, dok drugi označava postvarujuće tendencije dominantnog pristupa politike priznavanja (Fraser, 2000.). Zapostavljanje veza između obrazaca različitosti i nejednakosti u društvu povezano je s time što se problematika nepriznavanja u osnovi tretira kao kulturno uvjetovana psihološka "povreda”, koja nije izravno povezana s ekonomskim uzrocima, dok se istovremeno prelazi preko toga da su ekonomski i kulturni faktori međusobno nesvodivi uzroci društvene nepravde, da su obično isprepleteni te da se u pravilu uzajamno pojačavaju. Postvarujuće tendencije politike priznavanja dolaze do izražaja kada se postojeće kulturne karakteristike tretiraju kao dane, a zanemaruju se identitetske razlike unutar manjinskih grupa. Posljedica toga je da se generira pritisak za prilagodbom zajedničkoj kulturi, dok se potencijalno obeshrabruju vrijednosno-normativna propitivanja i moguća odstupanja od proklamiranog kulturnog modela. No kako proizlazi iz analize, upravo je mogućnost propitivanja postojećih kulturnih obrazaca važan uvjet za svrsishodno aktiviranje i politiziranje pasivnih identiteta (Bradley, 2016.). Glavni je razlog za to što priznavanje manjinskih identiteta nosi sa sobom mogućnost iskrivljenog priznavanja (engl. misrecognition) kod kojeg pripadnici manjina u svojoj borbi za društvenu emancipaciju mogu zastupati upravo one vrijednosti koje ih označavaju kao podređene. Bourdieu tu kontradikciju objašnjava nesvjesnom internalizacijom društvenih odnosa dominacije koja svoj izraz nalazi u dispozicijama habitusa. Ili drugačije rečeno, „podređeni uvijek doprinose svojoj podređenosti“ (Bourdieu i Wacquant, 1992.:24) jer su dispozicije koje ih na to navode rezultat nesvjesne prilagodbe na klasom, rodom ili etničkom pripadnošću ograničene mogućnosti djelovanja. Na mogući izlaz iz te kontradiktorne pozicije upućuje stajalište N. Fraser (1997.), koja svojim transformativnim pristupom politici priznavanja nudi alternativu dominantnom, kako ga ona naziva, afirmativnom pristupu. Za razliku od afirmativnog pristupa, koji pretpostavlja da su postojeći identiteti legitimni i autentični izrazi kulturne 
različitosti, transformativni pristup podrazumijeva da su postojeći identiteti vezani uz postojeće odnose dominacije. To znači da transformativni pristup identitete promatra kao sociokulturne konstrukte koji odražavaju odnose između različitih grupa u društvu. Stoga, mijenjanje postojećih odnosa dominacije između grupa pretpostavlja i mijenjanje postojećih grupnih identiteta - u idealnom slučaju manjinskih i većinskih (usp. Bourdieu, 2011.). Ta promjena značila bi, u osnovi, promjenu osnovne dihotomne (mi - oni) strukture, koja odlikuje većinu grupnih identiteta (usp. Blell i Doff, 2014.), kako bi se na taj način otvorio prostor za fluidnije, potencijalno debinarizirane simboličke strukture. Ranije je spomenuto da se taj pomak od dihotomnih „mi - oni” identiteta prema inkluzivnijim višestrukim identitetima u literaturi opisuje pojmom hibridizacije. Osnovna karakteristika „hibridnih” ili, kako ih S. Hall naziva, kulturnih identiteta jest da se u različitim kontekstima pojedinci i grupe kao subjekti mogu na različite načine pozicionirati unutar relevantnih povijesnih i kulturnih narativa. To znači da su identiteti u osnovi posredovani diskursom zbog čega se o njima može pregovarati u javnom prostoru (primjerice, političkom ili umjetničkom) (Auernheimer, 2003.). Na taj način identiteti ostaju trajno otvoreni za nove interpretacije ili Hallovim riječima: „Na različitim mjestima, vremenima, u odnosu prema različitim pitanjima, granice se premještaju. One postaju, ne samo ono što su, u određenom vremenu, zasigurno bile - uzajamno isključujuće kategorije, već i ono što ponekad jesu - različite točke na kliznoj skali” (Hall, 1990.:228). Važno je istaknuti da Hall svoju teorijsku poziciju gradi na iskustvu tzv. „novih dijaspora“ nastalih kao posljedica postkolonijalnih migracija u drugoj polovici 20. stoljeća. Njihovi pripadnici morali su naučiti kako usvojiti novu kulturu bez napuštanja stare koja ih je prvotno oblikovala. Trebali su naučiti prevoditi i pregovarati između kultura i pritom „odbaciti san ili ambiciju ponovnog otkrivanja bilo kakvog oblika 'izgubljene' kulturne čistoće...” (Hall, 1992.:310). Opisana kulturna izmještenost „novih dijaspora” otvara prostor i mogućnosti za "transformaciju koja prati nove i neočekivane kombinacije ljudskih bića, kultura, ideja, politika, filmova, pjesama" (Rushdie prema Hall, 1992.:311). Potonji citat upućuje na to da Hall, koji prenosi navode pisca S. Rushdiea, potencijal za razvoj hibridnih višestrukih identiteta vidi primarno u području kulture i umjetnosti (usp. Hall, 1990.) ili preciznije u „korištenju resursa povijesti, jezika i kulture”, koji nam omogućavaju da razumijemo "kako smo bili reprezentirani i kako je to povezano $s$ time kako bismo se sami mogli reprezentirati" (Hall, 1996.:4). No stječe se dojam da Hall pritom tendira apstrahiranju socijalnog konteksta mogućih identitetskih (re) pozicioniranja. Iako se navodi da su kulturni identiteti predmet trajne „igre” „povijesti, kulture i moći”, ne adresiraju se nejednake mogućnosti sudjelovanja u toj „igri”, tj. postojeće razlike u pristupu povijesnim i kulturnim resursima na klasnoj, rodnoj ili etničkoj osnovi. U tome Hallova pozicija nalikuje razmotrenoj politici priznavanja, koja zagovara kulturnu politiku različitosti nezavisno od društvene politike jednakosti. U konačnici i jedna i druga pozicija zanemaruje, kako naglašava Fraser, da se „kulturne različitosti mogu slobodno elaborirati i demokratski posredovati samo na temeljima društvene jednakosti” (Fraser, 1997.:186). Dublji uvid u važnost politike jednakosti 
o kojoj govori Fraser pruža nam koncept habitusa, koji u osnovi opisuje strukturalne limite svake refleksivne rekonstrukcije identiteta (Bottero, 2010.). Time što naglašava situativni i utjelovljeni karakter subjektivnih dispozicija koncept habitusa objašnjava zašto se aktivacija i politizacija pasivnih identiteta ne može ograničiti na repozicioniranje unutar diskurzivnih konstrukata, o čemu govori Hall. Drugim riječima, koncept habitusa važan je jer s jedne strane govori o važnosti višestrukih identiteta za politiku priznavanja (nasuprot mogućnostima postvarenog ili iskrivljenog priznavanja), a s druge strane o uvjetima za njihovo politiziranje, pregovaranje i eventualno usvajanje.

\section{Literatura}

1. Auernheimer, G. (2003). Einführung in die Interkulturelle Pädagogik. Darmstadt: Wissenschaftliche Buchgesellschaft.

2. Barry, B. (2006). Kultura i jednakost. Zagreb: Jesenski i Turk.

3. Bell, L. A. (2016). Theoretical Foundations for Social Justice Education, in: Adams Maurianne; Bell Lee Anne; Goodman Diane J. and Joshi Khyati Y. (Ur.). Teaching for Diversity and Social Justice. New York: Routledge.

4. Blell, G. and Doff, S. (2014). It takes more than two for this tango: Moving beyond the self/other-binary in teaching about culture in the global EFL-classroom. Zeitschrift für Interkulturellen Fremdsprachenuntericht, 19 (1): 77-96.

5. Bottero, W. (2010). Intersubjectivity and Bourdieusian Approaches to „Identity“. Cultural Sociology, 4 (1): 3-22.

6. Bourdieu, P. (1977). Outline of a Theory of Practice. Cambridge: Cambridge University Press.

7. Bourdieu, P. (1990). The Logic of Practice. Stanford: Stanford University Press.

8. Bourdieu, P. (2011). Distinkcija. Zagreb: Antibarbarus.

9. Bourdieu, P. and Wacquant, L. (1992). An Invitation to Reflexive Sociology. Cambridge: Polity Press.

10. Bradley, H. (2016). Fractured Identities: Changing Patterns of Inequality. Cambridge: Polity Press.

11. Chua, A. (2018). How America's identity politics went from inclusion to division. The Guardian. https://www.theguardian.com/society/2018/mar/01/howamericas-identity-politics-went-from-inclusion-to-division. (Pregledano 04. studenog 2020.)

12. Cooke, M. (2009). Beyond Dignity and Difference: Revisiting the Politics of Recognition. European Journal of Political Theory. 8 (1): 76-95.

13. Fraser, N. (1997). Justice Interruptus: Critical Reflections on the "Postsocialist" Condition. London: Routledge.

14. Fraser, N. (2000). Rethinking Recognition. New Left Review, (3): 107-120.

15. Habermas, J. (1994). Struggles for Recognition in the Democratic Constitutional State, in: Gutmann Amy (Ed.). Multiculturalism: Examining the Politics of Recognition. Princeton, New Jersey: Princeton University Press. 
16. Hall, S. (1990). Cultural Identity and Diaspora, in: Rutherford Jonathan (Ed.). Identity: Community, Culture, Difference. London: Lawrence and Wishart.

17. Hall, S. (1992). The Question of Cultural Identity, in: Hall Stuart; Held David and McGrew Tony (Eds.). Modernity and its Futures. Cambridge: Polity Press.

18. Hall, S. (1996). Introduction: Who Needs „Identity“?, in: Hall Stuart and du Gay Paul (Eds.). Questions of Cultural Identity. London: Sage.

19. Isin, E. F. and Wood P. K. (1999). Citizenship and Identity. London: Sage.

20. Jenkins, R. (1982). Pierre Bourdieu and the Reproduction of Determinism. Sociology, 16: 270-281.

21. Jenkins, R. (1996). Social Identity. London: Routledge.

22. Kelly, P. (2002). Introduction: Between Culture and Equality, in: Kelly Paul (Ed.). Multiculturalism Reconsidered. Cambridge: Polity Press.

23. King, A. (2000). Thinking with Bourdieu against Bourdieu: A "Practical" Critique of the Habitus. Sociological Theory, 18 (3): 417-433.

24. Kymlicka, W. (2002). Contemporary Political Philosophy: An Introduction. Oxford: Oxford University Press.

25. Kymlicka, W. (2003). Multikulturalno gradanstvo. Zagreb: Jesenski i Turk.

26. Lauder, H.; Brown, P.; Dillabough, J.-A.; Halsey, A. H. (2006). Introduction: The Prospects for Education: Individualization, Globalization, and Social Change, in: Lauder Hugh; Brown Philip; Dillabough Jo-Anne; Halsey A. H. (Eds.). Education, Globalization and Social Change. Oxford: Oxford University Press.

27. McNay, L. (1999). Gender, Habitus and the Field: Pierre Bourdieu and the Limits of Reflexivity. Theory, Culture and Society, 16 (1): 95-117.

28. McNay, L. (2008a). The Trouble with Recognition: Subjectivity, Suffering and Agency. Sociological Theory, 26 (3): 271-296.

29. McNay, L. (2008b). Against Recognition. Cambridge: Polity Press.

30. Mead, G. H. (2003). Um, osoba i društvo. Zagreb: Jesenski i Turk.

31. Mesić, M. (1998). Da li multikulturalizam tali američki „kotao za taljenje“. Revija za sociologiju, 29 (3-4): 209-224.

32. Mesić, M. (2006). Multikulturalizam. Zagreb: Školska knjiga.

33. Morrow, R. A. and Torres C. A. (1995). Social Theory and Education. Albany: State University of New York Press.

34. Mouzelis, N. (2000). Sociologijska teorija. Zagreb: Jesenski i Turk.

35. Ogbu. J. U. (1982). Cultural Discontinuities and Schooling. Anthropology and Education Quarterly, 13 (4): 290-307.

36. Parekh, B. (2006). Rethinking Multiculturalism: Cultural Diversity and Political Theory. New York: Palgrave Macmillan.

37. Shim, J. M. (2012). Pierre Bourdieu and intercultural education: it is not just about lack of knowledge about others. Intercultural Education, 23 (3): 209-220.

38. Sorić, M. (2012). Refleksivnost u sociologiji Pierra Bourdieua: nadilaženje socioloških dihotomija. Socijalna ekologija, 21 (3): 329-344. 
39. Swartz, D. (1997). Culture and Power: the Sociology of Pierre Bourdieu. Chicago: The University of Chicago Press.

40. Taylor, C. (1994). The Politics of Recognition, in: Gutmann Amy (Ed.). Multiculturalism: Examining the Politics of Recognition. Princeton, New Jersey: Princeton University Press.

41. Weber, M. (1980). Wirtschaft und Gesellschaft. Tübingen: Mohr. 


\title{
Culture, Habitus, Identity: Rethinking some Presuppositions of the Politics of Recognition
}

\author{
Saša Puzić \\ Institute for Social Research in Zagreb, Croatia \\ e-mail: puzic@idi.hr
}

\begin{abstract}
The main aim of the paper is to examine selected elements of the multiculturalist politics of recognition, while considering the interrelations of cultural-identity and structural aspects of social practice. For that purpose: 1) key concepts of the multiculturalist theoretical position are presented; 2) Bourdieu's concept of habitus is discussed, which points to confinements and social derivatedness of subjective dispositions; 3) the relationship between the notions of habitus and identity is questioned and 4) the demands for recognizing minority identitites are associated with the demands for redistribution within the theoretical framework of N. Fraser. The analysis revealed that the shaping of existing identities towards more fluid and debinarized identity patterns is an important element for purposeful activating and politicizing of minority identities. This process needs to be based on the awareness of structural limits found in all reflexive reconstructions of identity.
\end{abstract}

Key words: culture, habitus, identity, multiculturalism, the politics of recognition, the politics of redistribution. 